\title{
Plato \& Dukor on Philosophy of Sports, Physical Education and African Philosophy: The Role of Virtue and Value in Maintaining Body, Soul and Societal Development
}

\author{
Ani Casimir \\ Department of Philosophy, Institute of African Studies, University of Nigeria, Nsukka, Nigeria \\ Email: cepperngo@yahoo.com
}

Received December $13^{\text {th }}, 2012$; revised January $14^{\text {th }}, 2013$; accepted January $28^{\text {th }}, 2013$

\begin{abstract}
To the question, "what is sports", or what is a good sports activity or event, I am sure Plato would know what to say, using references to his philosophical division of man into three parts, namely: the appetite soul; the emotional soul and the reasonable soul. Plato would have said that sports comes from the human person and being, and so, for any particular sports to be accorded the accolade of goodness it must have the correspondence of the three constituent parts of man's true nature. The concept of the soul in Plato is what exploring just as that of Professor Maduabuchi Dukor's expositions concerning the African philosophical concepts of soul, mind, spirit and body as they affect philosophy of sports and the discipline of physical education. The article will therefore analyze the link between Plato concept of the good sports, Professor Dukor's ontological ideas about the African core values as they affect the balance, harmony and health both the mind and body of the human being. The central point here is the analytical framework of enquiry which Plato sustained in his Dialogues when he queries people: "what is this?”. By this he wants people to appreciate the fact that when they are in search of truth, they usually have the impression that they have all when, actually, they have only half-baked understanding of issues. It is important therefore to understand the issues involved in the disciplines of physical education, philosophy of sports, ethics and the ontological frame of African philosophy as profiled under Professor Dukor theistic humanism of African philosophy. Centrally, the dialectical link between Plato and Dukor will expose the ethical dimension to sports development since every thing is not wining and money or drugs should not be the ultimate motivation for sports and physical exercises. The exercise of sports should lead to the dual development and balance of both mind and body; the highest being the competition of the soul with itself and not with others in which laurels, gold or money is won or lost. The man who wins is the one, like in the communal spirit of the African ontology, who has conquered over his selfishness and sacrifices for the good of the community.
\end{abstract}

Keywords: Theistic Humanism; Values; African Philosophy; Philosophy of Sports; Physical Education; Platonic Idealism

\section{Introduction}

One of the most intriguing aspects of the Platonic dialogue and inquiry concerning the basic issues of existence is his exposure of the total or visible ignorance of people involved in both private and public discussions with him. The path of Plato's philosophic ascension into truth exposes the incomplete and half-baked comprehension of his co-contributors to every philosophical forum convened in the Republic. As in the past, the questions could be put before us either in the disciplines of philosophy of sports, or physical education: "what is good sports?"; "what is the role of ethics in sports development?"; “what is philosophy of sports?”; “what is physical education?”, or, actually, "what is the relationship between all these fundamental issues and how do they relate to African philosophy, especially the core values related by him under his concept of theistic humanism? It when issues and critical questions such as these that people now know that they lack a full comprehension of what things are implicit and explicit in conceptual enquiries about truth. The awareness of incomplete conceptual grasp or cognition of an issue should be the goal of every rational being, especially in understanding the real existential purposes why people indulge in sports or play games. Metaphorically, the game of life is an extremely philosophical an ethical business in which people should integrate the values and be virtues in their sporting objectives and goals. People trained and well educated in the philosophy of sports and physical education should be idealistic in the highest goals of wining, not over others alone but over their lower selves so as to discipline their weaknesses of self and selfish sporting objectives. If they assume and practice these higher sporting goal and ideals they should then use the ideals of the Olympics as their mirrors and strategic targets of wining or losing. Ironically if they lose in the material field of play, they should not at the same time lose their game of self control and mastery over their self ethical discipline; if they win in the material field of play they should not lose sight that the best wining is yet the moral mastery of soul over their selfish content and hubris. This is the essence of gamesmanship, sportsmanship and the Olympic ideals. The role of ethics or virtue ethics has been less clear than it can and should be, espe- 
cially in sports. It is important that we should shed some light on these confusions and then close with a few thoughts on the distinctive contribution virtue ethics can make to sporting and ethical relations. Daryl Koehn (1995) contributed to the enquiry by separating several key topics or issues that often arise when virtue ethics are discussed in every day context such as business or, for me, in a sporting space and time context:

1) What is an ethic of virtue, and how, if at all, does it differ from the other ethics offered by deontologists, utilitarians. Stoics, etc.?

2) What is the relation among these various ethics? In particular, does virtue ethics ground these ethics or vice versa? Or are the ethics equally fundamental and thus best viewed as complements to one another?

3) If each ethic offers discrete and distinctive insights into what constitutes moral human behavior, what contributions does an ethic of virtue offer. While distinct, these three questions are clearly interrelated in a number of ways. For example, what insights each ethic offers depends upon the tenets of that ethic. However, since my space here is limited and since the second question of the foundational status of the various ethics is quite complex, I will limit my comments to the first and last questions concerning the character of virtue ethics and its value in the study of business practice.

He therefore linked virtue ethics as ideal to every human activity, given that every action is performed by an agent and has an outcome, every ethic in some fashion must treat of outcome, act and actor. This observation has Led Daryl Koehn to observe that the various ethics of virtue only differ with their area of focus and their consequences to societal development:

The different ideas of virtue ethics have led some to conclude that the various ethics are best seen as differing according to where they put their primary focus. Thus virtue ethics is sometimes described as emphasizing the character traits of the agent, while utilitarianism concentrates on outcomes and deontological ethics on the act itself. However, this description of virtue ethics is somewhat misleading because outcome and act are central to the workings of a virtue ethics such as Aristotle's. For Aristotle, character development is an inevitable outcome of the act. Consequently, outcomes are every bit as important in Aristotle's ethics as they are in John Stuart Mill's as ideal character and behavior result from the content of each ethic.

The development of character and behavioral ideals should be the goals of competitive or any aspects of sports. In the last decade, among the different sub-disciplines of philosophy and the philosophy of sport, there is no doubt that the sub-field "ethics of sport" has been expanding and growing for the same reasons of clearing some confusion surrounding the precise nature and scope of the concept "sports ethics", philosophy of education. Professor Dukor's humanistic theism and Plato's concept of the good spors will contribute no doubt to this expansion in understanding and conceptual clarity itself. The achievement of dissipating conceptual confusion will result when we observe some important distinctions and contributions from these areas that have helped to built the ethical and moral ideals that have brought about this transformation in rational sporting thinking. McNamee, M. J. and Parry, S. J. (Eds.) (1998), in their work on the Ethics of Sport Edited Collections and Anthologies, Jim Barry introduced the summary of their work,

This volume was the first international edited collection of essays in the ethics of sports and made a very significant contribution to establishing the field of sports ethics. Its scope was broad and included topics from East and West but also included representatives from a variety of philosophical perspectives. It attempted to explore the links between sports ethics and what is sometimes referred to as "mainstream" philosophy, various traditional contexts for sports ethics (Physical Education and Coaching) and to raise contemporary issues with some philosophical depth. It was only partly intended as a teaching resource, operating at a fairly advanced level, but the paucity of available literature at the time meant that it became used internationally as an undergraduate text also. Since that time, with the development of many more resources, it tends to be used as a text in graduate classes.

The "Ethics of sports" went further to take a critical look at the contribution of Philosophy to sports development by as king questions such as "are there philosophical issues with respect to sport (other than ethical ones)? (Graham McFee); is Metaphysics: a precursor to good sports ethics (R. Scott Kretchmar); what is the erelation between ethics and the double character of sport: an attempt to systematize discussion of the ethics of sport (Johan Steenbergen \& Jan Tamboer) .It also evaluated the concept of Fair Play and Sporting Behaviour by critiquing games, rules and contracts (Simon Eassom); fair play: historical anachronism or topical ideal? (Sigmund Loland); respect for persons in sport and games (Cei Tuxill \& Sheila Wigmore). Most importantly, it examined the relationship between ethics, physical education and sports coaching as it asked a fundamental question: what moral educational significance has physical education? A question in need of disambiguation (David Carr). Significantly, one central discourse in the book relates to the moral development research in sports and its quest for objectivity (Russell Gough); building trust as virtues and rules in the ethical conduct of sports coaches (Mike McNamee) and the contemporary ethical issues in sports development. The segment of the this seminal contribution that relates to the theistic humanistic values of Professor Dukor has to do with the aspect that looks at multinational sport and literary practices and their communities: the moral salience of cultural narratives (William J. Morgan); violence and aggression in contemporary sport (Jim Parry); cheating and self-deception in sport (Gordon Reddiford); private autonomy and public morality in sporting practices (Terence J. Roberts) and exploring the relationship between Heidegger and sport (Paul Standish). In the book, Sport, Play and Games Suits, B. (2005), as reviewed by both J. S. Russell and Steven Edwards in Sport, Ethics and Philosophy, Vol. 1, No. 1, pp. 105-112, the relationship between sports and ethics is given further insight:

This is the most widely discussed book in the philosophy of sport, yet it was not really conceived as a book in the philosophy of sport. Suits's primary concern is to respond to Wittgenstein's claim that it is not possible to define terms such as "game". Suits disagrees, and defines games as "the voluntary attempt to overcome unnecessary obsta- 
cles”. Suits explains sport as a subset of games; they are games which require physical skill, have stability and a wide following. Suits also makes the additional claim that games should be thought of as central to any conception of Utopia. All this is done through the medium of a dialogue between the Grasshopper of Aesop's fable and his disciples (the most prominent of which is named Skepticus) on the nature of the good life.

In all aspects of sports these ideals are enshrined as fair play in the field of sports which players and competitors should emulate. When sports players and competitors have and embed these ideals in their sporting attitudes, then they a good philosophy of sports; when the graduates of physical education graduate from the their colleges and Universities, then they are good graduates who could inject human and ethical values of communalism into sports activities in Africa. The search for this full conceptual grasp should begin with our understanding of what is sports; what is good sports; what is philosophy of sports; what is physical education and what is the implications of the platonic reasonable soul to self knowledge and Dukor's concept of African philosophy as projected under his theistic humanism and the ethical body with the communal values of serving and living for others in the community rather than just to win or compete with others. This critical understanding of these basic concepts as revealed in the disciplines of physical education, philosophy of sports, ethics and African philosophy will be used to illustrate the truism and principle that good sports is wining over one's selfishness and living for the good of others in the African community. In African today sports should not create ill-feeling or hatred between competitors but the good feeling of neighborliness, peace, self and community sacrifice. This should lead us to identify the three parts of the soul and their corresponding implications and levels for sports development for the modern Africa. Plato's basic concepts of his philosophy relates to his hierarchical division of the human soul into three parts viz the appetitive soul; the emotional soul; and the reasonable soul. Sport is a fundamentally a human activity initiated by man; hence, its activity could be divided into the three parts of the soul as correspondence to measure and evaluate their quality. In the same vein, what is good sports must follow from what is good philosophy of sports, ethical values and curriculum of physical education. In Professor Dukor's theistic humanism of African philosophy man's essential humanity comes to the fore when his values serve and promote the development of the community. Such values which derive their power from the theistic human values of African philosophy, according to him is the saving value of the philosophy of humanism; as theism and its spiritual powers inject and empower humanism with values. What good sports does for the modern African should be the opportunity offered to construct the sports environment for these core human values of self/soul knowledge, selflessness, community and heroic sacrifice are blossomed and encouraged to be part of the template of human and societal development in the millennium. Derived from human being also the goodness of sport can be divided into three stages. Today, all over the world, sports has lost its ethical potency and theistic implications to bring out the ethical values of the three parts of the soul. Its only the lowest part defined as appetitive which makes people to compete to gain material goods through prizes won at competitions and at sporting events. The second stage of sport corresponds to the second part of the soul-the emotional soul which constrains competitors to bid for honor, name or glory, leading to increased self pride and arrogance of individual beings thinking they that are superior to others. This again cannot help to beauty or evolve the communal spirit in sports nor lead to heroic sense of self sacrifice for the community as evidenced in Professor Dukor's concept of theistic humanism in African philosophy. In consideration of the three soulful constituents of the human being, the third part of the soul - the reasonable soul is the best and most superior since the individual brings out his best in ethical values and attitudes for the good of others in his community having already attained the highest level of defeating his selfishness, ego and weaknesses. He now engages in the competition with his lower self and defeats it; leading to his blossoming of selfless and the most beautiful aspects of the soul's values which are essentially derivatives from the theistic quotient of man's humanism. This level of part of the soul makes it unnecessary for man to compete with man, which if it is done, then the competition will be done in the true spirit of the games or gamesmanship and sports development. This leads to perfect harmony of both the mind and the body of man and enhances the fluid movement of the physical and soulful contents of the sports person. The content of a good physical education philosophy should such that will reflect these core values as defined under African philosophy and captured the by the theistic ideals of Professor Dukor. This component and its ideals could be achieved by everyone who sincerely engages in sports development at either the local, state, national regional or global levels. Sports development leads and flows from sports ideals and core values. These ideals develop man and society beyond the ken of the physical body, selfish interests, environment, space and lead to collective self fulfillment for man and his society without regard to his/her physical abilities in comparison with others. In his classical work Jernej Pisk, (2006), concurs and gives the following views concerning the platonic idealism and its value connotations in sports development:

In Plato's view, good sport is the sport directed toward the fulfillment of self, all the way to the ideal-the idea itself. And only sport like that can bring true contentment to the human-the reasonable being. With this sport is essentially intervening in the sphere of philosophical cognition. The goodness of sport is no more determined by physical dimensions of space and time, but indeed, as Plato shows, the true good sport goes beyond these borders. In this manner sport goes beyond the physical world and touches the everlasting and unchangeable world of ideas. And the world of ideas is for Plato "tópos" where the very truth reveals itself. So, sport could be a useful means for the philosophical investigation of humans and the world.

\section{Physical Education Philosophy-Meaning and Concept}

The idea of physical education is an important part of the total educational program of any tertiary institution that is concerned with the production of educated graduates with the strong mind and a healthy body necessary for the building of good citizenship. The physical education program will provide students with physical activity opportunities both in and out of school through a differentiated program that fosters a lifetime commitment to physical activity as part of a healthy lifestyle. 
Physical education is an important part of a student's comprehensive, well-rounded education program and a means of positively impacting life-long health and well-being. Physical education will also instill students with the knowledge, skills, and values to make appropriate physical activity choices to integrate exercise into their lives. A good physical education curriculum should reflect a philosophy that delivers quality physical education under the instruction and supervision of a highly qualified physical education teacher. Our physical education program has the unique opportunity to develop health-related physical fitness and life-time activities that promote physical competence, cognitive understanding, and attitudes about physical activity so all students can develop healthy active lifestyles. High quality physical education enhances the physical, mental, and social/emotional development of every student and incorporates fitness education and assessment to help the students understand and improve their physical well-being. Quality physical education programs provide learning experiences for children that meet the developmental needs of students which helps improve their mental alertness, academic performance, readiness to learn and enthusiasm for learning. Fundamentally, philosophy of education conceives physical education as that integral part of the curriculum that, through human movement, concentrates on the development of individuals' maximum physical potential and their related social, emotional, and ethical intellectual growth. The discipline's primary purpose is to assist the learner in developing:

1) Total physical fitness and lasting desire to maintain it;

2) Movement abilities ranging from functional life skills to those needed for successful participation in leisure activities of their choice;

3) A sense of self-worth and dignity;

4) Social competencies;

5) Safety awareness; and

6) An appreciation and understanding of specific sports and dances, including their origins, cultural impact and aesthetic values.

In this context, we could say that the truly physically educated student will have acquired both competencies applicable to any lifetime activities and a desire to retain the healthy feeling associated with fitness and exercise. One could conjecture with all amount of philosophical wisdom that any person in life goes through the course of physical education in any higher institution should have the opportunity to participate in sports either as a coach, facilitator, teacher or athlete and reflect the core ethical values a s defined by Plato and Dukor as core values in sports. Moreover, the graduate, according to the essential guides of physical education (2012) should outside the ethical also have the life opportunity to:

Demonstrate motor skills and movement patterns to perform a variety of physical activities; understand movement concepts, principles and tactics as they apply to the learning and performance of physical activities; utilize appropriate motor skills, tactics and movement concepts/ principles while participate regularly in physical activity; achieve and maintain a health enhancing level of physical fitness; demonstrate responsible personal and social behavior in physical activity settings.

Seen from another dimension, physical education is defined in the Wikipedia (2012) with a more complete morphological and epistemic depth that helps the learner to acquire mental, ethical and physical skills:

Physical education (often abbreviated Phys. Ed. Or P.E.) or gymnastics (gymor gym class) is a course ... that encourages psychomotor learning in a play or movement exploration setting. [Physical education trends have developed recently to incorporate a greater variety of activities. Introducing students to activities like bowling, walking/hiking, or Frisbee at an early age can help students develop good activity habits that will carry over into adulthood.] Some teachers have even begun to incorporate stress-reduction techniques such as yoga and deepbreathing. Teaching non-traditional sports to students may also provide the necessary motivation for students to increase their activity, and can help students learn about different cultures. For example, while teaching a unit about lacrosse (in, say, Arizona, USA), students can also learn a little bit about the Native American cultures of the Northeast and Eastern Canada, where lacrosse originated. Teaching non-traditional (or non-native) sports provides a great opportunity to integrate academic concepts from other subjects as well (social studies from the example above), which may now be required of many P.E. teachers. The four aspects of P.E. are physical, mental, social, and emotional. This push towards health education is beginning in the intermediate level, including lessons on bullying, self esteem and stress and anger management.

\section{Understanding Philosophy of Sports}

Philosophy of Sport is an introduction to the discipline of philosophy by way of questions that arise in the context of sports. In other words, the questions we pose, assists the enquirer to move towards philosophical questions by working through more practical questions that we ask ourselves in the context of sports. These questions also border on the ethical issues that relate to sports development. Professor Blattner ${ }^{1}$ agrees and elaborates further on the nature of this concept that will give us a clearer understanding of the philosophy of sports:

For example, what (if anything) is wrong with using performance enhancing drugs? Is it cheating? What is it to cheat? And what's wrong with cheating anyhow? Is it dangerous? Many sports are dangerous, some can even be life-threatening. So, what's wrong with something's being dangerous? And even if it is dangerous, does that give anyone aside from the athlete him- or herself the right to stop the athlete from using PED's? Is it unnatural? What does "natural" mean in the context of human beings? Lots of things we do are "unnatural" in some sense. Hi-tech sports equipment is "unnatural" in some sense. Another example: what's the difference between an amateur and a professional, and why does this distinction matter? Do amateurs play for "love of the game," while professionals earn money? Can't someone who earns money, even lots of money, playing a professional sport also or even primarily play for love of the game? Should collegiate ath-

${ }^{1}$ Professor William Blattner (1998). In his fall 2012 course syllabus gives the following definition of the philosophy of sports: Philosophy of Sport Philosophy 98, this course will be offered during the fall semester, 2012. Mosley Physical Education, Health and Sports and Department 2010-2011. 
letes be paid? Are big time collegiate athletes exploited by their institutions or by the television networks? Do the pressures of professional or collegiate athletics place an alienating barrier between the athlete and his or her sport? Between the athlete and his or her education? We all debate questions like these, and when we do we often hit barriers to our understanding. Those barriers are philosophical: What are the ethics of competition and games? May anyone dictate to an adult what he or she does to or with his or her own body? What is the distinction between the natural and the artificial? What is exploitation? What is alienation? These are all philosophical questions, and we will examine them through a range of literature, including contemporary contributions to the growing discussion of the philosophy sport and classical contributions by the great philosophers of the past (incl. Kant, Mill, Marx, and others).

\section{Plato on Good Sports and Values-An Ethical Challenge}

An examination of the platonic concept of sports will be treated from the perspectives of his concept, the human soul and modes of sports, how sports intervened into the sphere of philosophy and, finally, Plato's philosophy and the study of sports. Our treatment of this segment of the research will be drawn from the write ups of Jernej Pisk (2005). What is good sport: Plato's view and that of (2010) entitled "Ethics in sportsthe role of cardinal virtues in sports" with elaborations and insights which he has published that threw much insight into the relationship between sports, education, philosophy, ethics, human values and virtues as a multidisciplinary enterprise that draws up the resources of man's soul, mind, spirit, body and environment. This should be the focus of our discussion in the article.

\section{Plato's Concept of Sports}

On this issue, Pisk (2005) writes about the Grecian concept of culture as the environment that gave rise to sports and related activity such as music and entertainment, giving along the line the platonic concept of sports:

For the Greeks sport was a sign of their culture and something inherent. Therefore also Plato could not avoid sport. Gymnastics and music are for him two of the oldest parts of culture. Plato found the mission of his life in political activity - in education. So he touched sport many times in his dialogs and exposed its role in the education of young people. All education is directed to the development of virtue. The value of sport is above all in development of the virtue of fortitude. This is not surprising if we recall that Greeks before Plato had understood sport as agon, that is competition for glory and honor where at the same time also courage has to be demonstrated. Plato took over this understanding of sport; he deepened it and included it in his educational system. Plato likewise uses examples from sport in his dialogs many times to illustrate different truths from everyday life. He compares true philosophy with gymnastics in opposition to sophistry which is like cosmetics. All Departments of educational development is designed to make a solid ground in young people based on which they can enter the world of philosophy. Educa- tion through gymnastics and music in childhood was directed to make some customs regarding justice we will see, different modes of sport correspond to different stages of the human soul, we should first take a look at that division.

\section{The Human Soul and Modes of Sports}

In attempting to capture the Platonic idea of the good sports, Piski draws a fine distinction between the state, the soul and relates each segment of the soul to an attribute or virtue of the human being, bringing out the sporting implications:

Beside the doctrine of forms Plato is also well known for teaching the doctrine of the state and the human soul. The ideal state and the human soul have a very similar construction. The soul is just like a small state. Plato divides the state into three different classes: the lowest is the economic class, second is the military class and the third, the highest and the most noble is the governing class of philosophers. Every one of these classes has its own virtue. And those virtues are presented also in different parts of the soul: in appetite, emotion and reason. So, to the lowest part of the soul and to the lowest class in the state belongs the virtue of temperance. To the second part of the soul and to the second class of the state belongs the virtue of fortitude. And to the highest part of the soul and the highest class of the state belongs the virtue of wisdom. As we already have seen for Plato sport has value because it helps to develop the virtue of fortitude in the human soul and in the state. In both cases sport is a means of education in the second of the three stages, because it is connected with the second, emotional part of the soul and with the second military class in the state. So sport, as Plato had shown us, does not extend directly to the third or first part of the soul neither to the third or first class of the state. However, some modes of sport which are common today correspond to Plato's division of the state and the human soul. This can, at the same time, show us that sport is tightly connected with human being. In Plato's teaching the human is his/her soul. Different values of different parts of the soul can then reveal to us also different values of sport, because every mode of sport is founded on a different part of the soul. To three parts of the soul also three different pleasures are connected: "Because there are three parts of the soul-appetite, emotional and reasonable, there are also three different pleasures: pleasures connected with material things and riches (belonging to the appetite soul), pleasures connected with honor and victory (belonging to the emotional soul) and pleasures of cognition of reason".

From the Plato's reasoning the idea of conjoining sports development and the functions of the three aspects of the human soul is the surest way the best possible sport can be achieved. Sport like this presents human beings with the possibility of achieving the perfection of all of their potentials. This is what he calls the reasonable exercise of sports philosophy as physical education. Physical education should graduate teachers and students armed with the best ethical values that will result in reasonable sports activities through cognition. In the activities and cognition that are in accordance with reason the highest fulfillment, the true contentment of the human — the reasonable 
being can be found. With this sport essentially intervenes in the sphere of philosophical cognition-the sphere of searching and cognition of wisdom and knowledge; cognition of self and selfborders. At this point the question can rise if division of sport into three stages of goodness is not only a human construct which has no connection with reality? The answer based on Plato's philosophy is no. Because there is no sport in the physical world without humans; sport can become factual only through human beings and a human being is for Plato as much as a human soul, therefore it is evident that a human soul has direct influence on sport. So this division of goodness of sport is based on the fact of reality of the human being as Plato had understood. Besides this, this kind of division of sport is also adjusted to generally accepted values of different modes of sport, e.g. educational sport, recreational sport and professional sport.

\section{Intervening of Sports into the Sphere of Philosophy}

As we can deduce from the platonic view of sports given above, sports and philosophy enjoy a paternal and dialectical relationship which started at the beginning of Greek philosophy. Thus Piski agrees that sports extends naturally into the domain of the philosophical enterprise. Why Plato chose only the third part of the soul as the best entry point for philosophical foray into sports development is another source of speculation for philosophers such as Piski who gives the following perspectives:

But why is the sport of the third part of the soul the best in doing this? Sport like this is similar to philosophy because they both use the same highest human capability_reason. Sport of this kind can lead humans to philosophical cognition of themselves. Through sport like this the human being is most revealed. Revelation of truth with reason leads to the highest human happiness, as Plato said. To show that philosophical cognition is of the highest value and the source of highest happiness Plato used an example from sport: "He (an athlete) only gives you the appearance of happiness, and I give you the reality.” But now it is clear that also sport can be a means of philosophical cognition of truth and the source of true happiness. Just like the rulers in a state also sport of the third stage intervenes into the sphere of philosophy, because it has its origin in the reasonable part of the soul. By using the mind (intellect), sport extends over the physical world and touches the everlasting and unchangeable world of forms. And the world of forms is for Plato topos where the very truth is being revealed.

\section{Plato's Philosophy and the Study of Sports}

Finally we come to the study of Plato and his works in the study of sports. We can effectively argue that although in his works, 'Plato mentioned sport quite often and integrated it into his educational system he never asked the fundamental philosophical question; a question which he often asked his cospeakers in dialogs and with which he brought them to the cognition of their ignorance; the question "What is something?” So: What is sport? There is no doubt that he would also bring us to the cognition of our ignorance'. In seeking to conquer this human ignorance, Piski concedes that the Plato's critical enquiry helps us to acquire new understanding and that 'this cognition allows us to start walking on the path of philosophy. For instance, it is necessary firstly to know a human individual to get to know how he or she can become better. "Can we ever know what art makes us better, if we do not know what we are ourselves?" Or: "Should we ever have known what art makes a shoe better, if we did not know a shoe? Impossible! Only good knowledge of a thing allows us to be good in handling it. This is true for shoes and also-because of our complexity even more so-for human beings and, last, but not least, also for sport. So, when we have long discussions about sport, we should first answer Plato's question of what something is, what is sport? Plato's intention is not to destroy something, but to build on a solid ground of truth itself. If we interpret Plato's philosophy in that way, as stimulation for philosophy, it still is of great value.' In the following arguments made below, Piski continues to elaborate and to draw out finer distinctions that define the difference between the materialism of present day sports in which money, honor and laurels are the only things fought for with the spiritual idealism of true sportsmanship, gamesmanship and participation. In current times when wisdom is a "mass phenomenon" and when-to oppose true wisdomone "wisdom" is contrary to another, this need for searching for real wisdom is even bigger. Plato found the value of sport in the second part of the soul. This part of the soul owns fortitude and seeks fulfilment in pleasures of honor and victory. In this we can find the elementary ancient agon and the origins of sport in ancient Greece. As we know at first the only prize for victory was a wreath and honour. But later material prizes became more and more important. From this it is clear that when sport lost its sources in agon (based in the second part of the soul) and got its motive and fulfilment from material prizes, it was degraded to the lower and worse pleasures of appetite soul. This materialization of sports and competition does harm to the noble concept of sports philosophy, and, as noted below by Plato, humiliates and negates the true essence of sports:

The fact that this became the main reason for sport represents - from the philosophical point of view — a step back. Sport in which money and material prizes are in the first place (sport in the service of money and not money in the service of sport) is in Plato's eyes degraded and the worst possible sport because in it there is no place for philosophy, for love for wisdom, cognition of the soul, etc. Sport like this is humiliated sport if we compare it with the sport for honour and glory, because it fulfils only the lowest (appetite) part of the soul while the emotional and reasonable part of the soul which are the special properties of humans remain unfulfilled. If sport which is based on the appetite part of the soul and seeks its fulfillment in getting material prizes is the worst, then sport which extends to the third part of the soul is the best. This sport is superior because it corresponds to the reasonable human soul and is connected with pleasures of cognition. But, where we can find sport like this? If we can find the first kind of sport where material prizes are involved and the second where honor and glory can be reached, then we can search for the third kind of sport only outside "sport for money" or "sport for glory". Both, money and glory, do not originate in the human but come from the outside and do not depend on the particular human. As Aristotle found out glory is independent of him because only another human can give honor to the first one. 
The concern of good sports should be the wellbeing of the soul, in the first place, and the happiness and harmony of the body in relation with the values identified with the soul. So we must search for the third kind of sport in tight connection with humans themselves. And this is in the first place competition with the self. The aim for this can be to attain perfect execution of a movement or exercise that can be only achieved with tight cooperation with reason. We can say that it is the highest union between body and soul, the full harmony of body with the instructions that flow with moral values that seek to establish the good of all members of the community and not the selfish interests of wining alone by individuals. These where the Platonic concept of sports philosophy finds philosophical resonance with Professor Dukor's African philosophy and communal values. To the exposition of that dialectical nexus between Plato and Dukor, we must turn our critical mind to and bring out its finer implications for the philosophy of sports and physical education.

\section{Dukor, African Philosophy on Soul, Body and Communal Values-Compliment to Good Sporting and Physical Well-Being}

In the first place the materialism and idealism of sports and competitions have been used by both Plato and Dukor to do an abiding critique of the abuse of modern day sports as concept and analogy for building the well being of both individuals and the society at large. The Dukorian concept of idealism (2010: pp. 1-3) matches and compares effectively with the Platonic ideas and idealism that define good sports and what should define the content and framework of the good sports person in African philosophy and tourism. Elaborating upon the distinction between "idealism and materialism" Professor Dukor writes (2010: pp. 6-9):

For proper understanding of the metaphysical doctrine known as idealism, it would be of utmost advantage to look at the meaning of the word "idea" for better understanding of the doctrine. The word idea is a transliteration of a Greek word of which the root meaning is "see". Plato writes ofa person as being "very beautiful in idea" meaning "beautiful in visual aspect”. In Plato's philosophy, the idea or forms are always spoken of as: the objects of intelligence, in contrast with the objects of perception, which are in a state of becoming; eternal in contrast with perishable world of change ... One of the most important and early modifications of this Platonic view is the religious conception of thee ideas as the thoughts of God. Idealsim is therefore a metaphysical doctrine that reality is intelligible or that reality is mental, that what is real is of immaterial susbstance.

The ideals that fire a man's thinking and actions in any area of life such as sports also emanate from his mind and the rational exercise of his rational soul. For Dukor, the mind, soul and the thinking structure of the African are the eternal source his theistic behavior and his social attitudes toward his fellows in the African society. Dukor draws out the finer relations between a man's mind, reason, thinking, happiness and the attainment of wisdom:

A man's way of thinking, his attitude, beliefs and opinion constitute a philosophy (Dukor, 2010). Our happiness, peace of mind and style of thinking or the philosophy of life, in general sense, when we speak of a man's philoso- phy, we simply mean the sum of his beliefs. His belief guides his thinking and actions about life. In contrasts to philosophy as personal ideas, beliefs and views about the world, philosophy as a preoccupation is a specialized quest for knowledge which in Platonic or African traditional thinking is called wisdom. A wise man in this sense has a clear understanding of the distinction between reality and its appearances. Man is not like other animals. He is a rational being and lives in the organized life of the society.

The rational being of Plato is much akin to the wise man who has acquired communal values that help him to relate very well with his fellows in the society. The wise man in Plato's sporting idealism has acquired the four selfless ethical virtues and values just as the ideal African sports person of Professor Dukor is a wise man who has not only acquired the four values, but has also suffused with the core African values and virtues that emanate from his regular and sporting cultivation of theistic humanism as life's philosophy. To understand the African athlete and his sporting attitudes is to examine the framework and content of this theistic humanism as a basic African philosophy. This philosophy makes the African athlete to be wise, prudent, disciplined and philosophical in his approach to sports development or participation or engagement. For him wining is not everything but self conquest to achieve the communal sacrifice for others in the sporting arena of life is the fundamental goal. The theistic humanistic values that emanate in the field of sports help the African athlete to be rational and communal in his thinking and attitudes towards others in the sporting arena; he shows that his soul, mind and body are in harmony in consideration of his fundamental African belief that all of parts of his being are united and harmonized and that his soulful and spiritual beliefs inform his values and sporting ideals. Therefore Professor Dukor, in his African philosophy and theistic humanism of soul, body and communal values constitute fundamental compliments to good sporting and physical well- being of the African athlete and helps the graduate of physical education and philosophy of sports to be balance, disciplined and stoical in management the dynamics, pains, gains, losses or victories of sports engagements and activities in an part of the globe.

\section{Defining an African Value based Philosophy of Sports}

In his work on "ethics in sports-the role of cardinal virtues in sports, Jernej Pisk Redefines the platonic approach to sports development and identifies the four virtues of justice, prudence (wisdom), courage (fortitude), and temperance (moderation, self-control). But when Plato was asked the question why he emphasized only the four he said that these four virtues represent the whole of virtues (Republic, 428a). According to "Pisk analysis (2010)" these virtues are evidently connected with Plato's construction of human soul. But these four cardinal virtues are not the only virtues, neither in Plato's philosophy, but they are the "hinges", on which all the other virtues turn. They are the necessary foundation and prerequisite for all the others. So, which role can be ascribed to cardinal virtues in sport? Jernej Pisk throws more insight into the value and virtue connection to sports development:

In the last decades virtue ethics in sport has gained much attention. This is not surprising because it seems that 
some characteristics of this ethical theory successfully respond to very complex situations in sport. The experience shows that merely rules of particular sport do not assure moral sport actions. Already Plato has pointed out that there are two guides of moral actions: laws (or rules) directing us from outside and virtues directing us from inside. He was convinced that virtues are better than laws, since it does not make any sense to promulgate laws among non-virtues persons, because they will disregard them. On the other hand the virtues people are able to find out what is good and what is not regardless of laws. Therefore, it is important to become a good person, since only then also laws or rules make sense. Plato exposes four main virtues: justice, prudence (wisdom), courage (fortitude), and temperance (moderation, self-control). They are the necessary foundation and prerequisite for all the others. So, which role can be ascribed to cardinal virtues in sport? For Plato the first and the most important is virtue of justice. It seems that it is also preferential in sport, especially when we think about sport competitions. But, as emphasized the medieval philosophy the source of justice and other virtues is reason. Reason is the essence of human nature and of all moral acts. Therefore to act in accordance with reason- to have the virtue of prudence is the first demand. While prudence refers to individual alone, justice refers to others. Every sport competition, contest, is therefore the field of virtue of justice. The basis of justice is to give everyone his due. Justice put us in a position of a debtor to a fellow-man. This requires that we play fair and honorable. Therefore donated victory is not righteous because it is not owed. Besides that, virtue of justice arranges matters between the individuals and between the individual and community which has a great impact on morality in sport.

This deep and conceptual analysis by Jernej Pisk has given and furnished us with the vital key fundamental insights into the areas African philosophy that could definitely contribute to the building of a value based philosophy of sports, physical education and general sports development as advanced by the two critical theories of Plato and that of Professor Maduabuchi Dukor in theistic humanism of African philosophy and values.

\section{Conclusion}

In African philosophy, most contemporary thinkers had been influenced by the four seminal contributions of Professor Maduabuchi Dukor that emanated principally from his concept of theistic humanism and its processional and philosophical core human values. On the other hand, in general classical philosophy, many contemporary thinkers and philosophers are returning to Plato and his thought. Actually his relevance has been much clarified by the thoughts of Pisk (2010) who thinks that:

Their understanding of Plato often becomes the central and most influential point of their thought. Actually studies of Greek philosophy do not have meaning only in themselves, but also as much as they touch us in our present time and situation. Therefore also our investigation of Plato's philosophy concerns us as much as it touches our situation and contemporary sport. We can repeat after Jaeger: "We started out with Plato to find a state. Instead, we have found a man” (Jaeger, 1973: p. 354). Or paraphrased: We start to closely examine a man and we found out which kind of sport is good. At this point Plato warns us that the true value and goodness of sport is not determined by the physical dimensions of space and time. The seconds and meters are no more important because true good sport goes beyond these borders since for true good sport the cognition and improvement of self are the most important and even essential. And these are not reserved for just a few top-level individuals but everyone is capable of attaining them. Therefore this has a much bigger, even universal value. Also professional sport-sport for money and for glory gets its value only when it is harmonized with the reasonable part. To nominate reasonable sport as the leader (manager) of other sports is like nominating the absolute and divinity for the first measure. So, Plato's final suggestion could be to try to build a state within us which only can lead to happiness of people as athletes.

Much of African philosophy has shifted from the debate about its existence or non-existence to that of organized creative deconstruction, construction and reconstruction of basic tenets of the canons of African philosophy and its different departments. African philosophy of sports should be defined and established as a growing discipline embedded with African values that could help African athletes, philosophers of sports and physical education to integrate the functional pillars of theistic humanism as foundations of defining what constitutes the good sports, who is a good sporting person and what should be a fair rule that regulate good sporting activity or what should constitute a good sporting attitude as conceived from the philosophical foundations of virtue and value by both Plato and Professor Dukor Maduabuchi. These two seminal sources should help us to establish an authentic African philosophy of sports and physical education curriculum in tertiary institutions in the Continent or outside. Thus it is only when, according to Reid (2002), we play or participate in sports in the most complete manner that we find fulfillment: "Only when we play a sport in the most complete manner possible we find fulfilment as athletes”. But Piski (2010) complements the social and communal spirit further as the basis of self fulfillment in the community of human relationships that make sporting activity a theistic and transcendental activity necessary for man's sustainable livihood in the new millenium:

Only if we work-always keeping in mind our own vocation, our own objectives - we find fulfillment as human beings. The achievement of the expected sporting aims and earnings must be supported by a reassessment of the vision of the athlete: from a social point of view —as an individual placed in a system of relations-and from a transcendent point of view-as a person.

The whole idea of reconstructing African philosophy in a manner that gives the discipline greater credibility and legitimacy from the point of view of Professor Dukor's theistic humanism is to evolve an abiding culture of humane and civilized communal values that will form the basis of establishing the wellbeing of the African person and building a better society filled with valuable human relationships. In that sense Plato and Dukor are philosophically soul brothers in seeking to redefine the concept of philosophy of sports and physical education 


\section{A. CASIMIR}

which will contribute to the de-materialization of the sports competitions and activities making sports once more a reasonable and noble activity of the human soul in the context theistic virtues and communal values.

\section{REFERENCES}

Daryl, K. (1995). A role for virtue ethics in the analysis of business practice. Business Ethics Quarterly, 5, 533-539.

Dukor, M. (2010). Theistic humanism of African philosophy. The great debate on substance and methodology of African philosophy. Saarbrucken: Lambert Academic publishing.

Essentials Guides (2012). URL (last checked 28 September 2012).

Sfinstructionalresources.wikispaces.net/.../Physical+E

Jernej, P. (2005). What is good sport: Plato's view. Acta Universitatis Palackianae Olomucensis Gymnica, 36, 67.
Jernej, P. J. (2007). Mislim, torej sem’ in vrednost športa danes (Cogito, ergo sum' and the value of contemporary sport). Šport, 1, 41-43.

Jernej, P. (2010). Ethics in sports-the role of cardinal virtues in sports. In M. Hosta (Ed.), A collection of essays. Ljubljana: International Institute for Sustainable Development, Policy, and Diplomacy in Sport.

Kreeft, P. (1986). Justice, wisdom, courage, and moderation: The four cardinal virtues. In Back to Virtue (pp. 59-70). San Francisco: Ignatius Press.

McNamee, M. J., \& Parry, S. J. (1998). Ethics and sport, with introduction. London: Routledge.

Plato (1974). Republic 443d. Study philosophy series. Harlow: Longman.

Ried, H. L. (2002). The philosophical athlete. Durham: Carolina Academic Press.

Suits, B. (2005). Sport, play and games. The grasshopper; games, life and utopia. Peterborough, ON: Broadview. 